\title{
The Audit Commission's review of mental health services
}

\author{
J. Renshaw
}

\section{The Audit Commission}

The Audit Commission is appointed by Parliament to oversee the auditing of all local authority services and NHS purchasers and providers. Audits are commissioned from both the District Audit Service and accountancy firms. Some 30 to $40 \%$ of the local audit work is classified as 'value for money' auditing, which examines the services provided, their quality, standards and management arrangements.

A limited number of 'value for money' topics are studied in any year, supported by a central research team which provides comparative national data to the auditors and publishes a national report. Audits of mental health service providers and purchasers (NHS and social services) will take place between November 1994 and summer 1995 and will produce a confidential report to each authority. The research team began its review in January 1993 and expects to publish the national report in late 1994, around the time that local audits begin.

\section{The review}

The study aims to address many of the current topical issues in mental health policy. For example, the number of NHS psychiatric hospital beds has reduced by about $50 \%$ over a ten year period, especially in the large, older hospitals. Most districts have established community teams and almost all have plans for such teams. Expenditure per head on mental health varies widely between districts - by a factor of seven and does not appear to be closely correlated with need. Recent high profile disasters and enquiries have generated national concern about mental health care. Purchasers have begun to develop monitoring arrangements which will sharpen up their demands on NHS providers. GP fundholders are becoming influential in shaping local priorities, a development which is causing concern to some providers.

The review is restricted to services for adults and it does not attempt to study specialist services for elderly people or those with drug and alcohol problems. The research team has visited 12 districts to interview representatives of NHS providers, purchasers, family health service authorities, social services, and service users, and to collect numerical data. In addition, a brief national survey is being carried out and further visits made to particularly interesting or 'good practice' services.

The quantitative data gathered from the 12 districts include:

a list of resources available from all providers, numbers of beds, places, teams, etc, and their costs. Purchase of services from other districts and independent providers is included

a profile of the caseloads of community team members and other community based professionals on a given date. This includes a classification of people into three groups, described below, and also length of time on the caseload, frequency of contact and care programme arrangements

Broad classification of need, based on diagnosis and history of service use:

(a) psychotic diagnosis, organic illness or injury AND

previous compulsory admissions OR

aggregate one year stay in hospital in past five years $O R$

three or more admissions in past five years

(b) psychotic diagnosis, organic illness or injury $O R$

any previous admissions in past five years

(c) no record of hospital admissions AND no recorded psychotic diagnosis, organic illness or injury

Please note that this information is intended to describe the caseload as a whole, not the needs of individual people.

cross matching of the community caseloads with users of other local services, to obtain a picture of the care packages received 
a list of the occupants of all acute hospital beds over a six month period with primary diagnosis, sector, consultant and length of stay.

The qualitative information collected from the 12 districts includes the management arrangements for teams and other resources, referral and admission criteria, multidisciplinary and multi-agency working, care programmes, re habilitation and continuing care services, user and carer involvement, out of hours services, provision for special needs such as ethnic minorities and reprovision strategies.

The national survey, carried out by local auditors, will provide a detailed list of the resources from all providers and their costs, together with a brief description of the management arrangements and care programme approach. The information will enable comparisons to be made between expenditure and resources in different districts. A comparative profile will be developed which will incorporate selected population and deprivation indicators.

\section{Initial impressions}

The information collected so far indicates a wide variation in expenditure between districts in relation to the population served. The balance of expenditure on different types of service such as NHS beds or peripatetic staff also shows considerable variation.

A number of issues and problems have been observed in relation to the management and quality of the services provided. For example, the management of beds, community professionals and other resources in a local area are often fragmented, which can lead to anomalies in admission criteria and a discontinuous service for users. Budgets are often insufficiently flexible at a local level to enable changes in staffing structures or innovative responses to be made to individual needs. The information available to clinicians, managers and purchasers is usually insufficient to enable adequate monitoring of the services provided or of their recipients. Training for many professionals has not fully addressed the needs of people in the community, particularly those with long term needs.

The development of care programmes is variable. Many providers have developed policies but encountered difficulties in putting them into operation, others have not yet established a clear policy. We have, however, observed a number of CPA systems which are working effectively, which have enhanced the communication between agencies and improved the care of vulnerable people.

These issues and others will be explored more fully in the national report to be published later in the year. More importantly, they will be followed up by trained local auditors in every district throughout England and Wales who will make specific comments and recommendations. tailored to the local situation.

J. Renshaw, Health Studies, Audit Commisston, 1 Vincent Square, London SW 1P 2PN

\section{Guidelines for submission of conference reports}

(a) Conference reports should not exceed 500 words

(b) The report should not be a detailed minuted account of the proceedings.

(c) Reporters should concentrate on the most interesting or original presentations. The aim of the report is to stimulate and inform readers and to give them a flavour of the highlights of the conference. Within the confines of a 500 word article, this means that most published reports will be highly selective accounts of the conference.

(d) Reporters should give their personal impressions of the conference, critically reviewing the meeting from the audience's perspective.

(e) Conference reviewers are encouraged to contact the Bulletin office before submitting their reports.

(f) The conference reports must be submitted to the Bulletin within four weeks of the meeting. 